\title{
STATE OF ART REVIEW OF SHAPE MEMORY ALLOY USED IN CIVIL STRUCTURES AS SEISMIC CONTROL DEVICE
}

\author{
Somraj Dhar ${ }^{1}$, Surajit Das ${ }^{2}$, Purnachandra Saha ${ }^{3}$ \\ ${ }^{1}$ M.Tech Student, School of Civil Engineering. KIIT University, Bhubaneswar, Odisha, India \\ (Email: somrajdhar@gmail.com) \\ ${ }^{2}$ Faculty, Department of Civil Engineering. NIT Agartala, Agartala, Tripura, India \\ (Email: surajit2006r@gmail.com) \\ ${ }^{3}$ Faculty, School of Civil Engineering. KIIT University, Bhubaneswar, Odisha, India \\ (Email: dr.purnasaha@gmail.com)
}

\begin{abstract}
Shape memory alloys (SMAs) are a kind of smart materials that "remember" their original shapes and can be utilized as an actuators that "change shape, stiffness, position, natural frequency and other mechanical characteristics in response to temperature or electromagnetic fields". SMAs exhibit two different phases i.e. martensite and austensite. Temperature and internal stresses (that play a role in super elasticity) determines the phases that SMA exhibits. The aim of this paper is to discuss about SMAs and its application in civil engineering structures like cable stayed bridges, elevated highway bridges, simply supported bridges and buildings as seismic control device. SMA is used as aactive, semi-active andpassive damper in civil structures. Passive damper has energy dissipation capacity and recentering ability. The recentering property areachieved by SMAs in austenite phase while dissipation ability of austenite is not so muchtherefore detwinning behaviour of SMA in martensite phase is considered increasing the damper's dissipating ability. NiTi SMAs showhigh level of superelastic hysteresis and energy dissipation and it solidify after transformation to stress-inducedMartensite, at roughly 6 to $8 \%$ strain. This property aremainly used for utilizing SMAs for hinge restrainer purposes for bridges. By using SMA's actuation property, Intelligent reinforced Concrete (IRC) was developed. IRC utilises strandedmartensite SMA wires for post tensioning and by monitoring electric resistance change of shape memory alloy wires, the strain allocation within concrete are obtained. If there is occurrence of cracks either by earthquakes or explosions, then by heating SMA wire strands results in its contraction and the cracks get reduced. It is observed from the study that SMA is effectively used as a seismic control device for civil structures.
\end{abstract}

Keywords: shape memory alloy (SMA), seismic control, bridge, building $* * *$

\section{INTRODUCTION}

The shape memory alloys are materials that have super elasticity and shape memory effect that other alloys and metals don't have. SMAs can be utilized as actuators that can "change shape, stiffness, position, natural frequency in response to temperature or electromagnetic fields". Use of SMAs for actuators had expanded range for various scientific fields of application.

Nickel-titanium alloys are mostly utilized SMAs. Other shape memory alloys consist of iron-manganese-silicon alloys, copper-aluminium-nickel and copper-zincaluminium. The generalized name for nickel-titanium alloy family is Nitinol. William J. Buehler, a researcher at the Naval Ordnance Laboratory in White Oak, Maryland identified Nitinol (Nickel Titanium Naval Ordnance Laboratory) of having shape memory properties.

Energy dissipation devices are designed to prevent damage to given structure by reducing structural seismic demand or absorbing excitation energy in special devices. Energy dissipation device can be used as viscous device, viscoelastic devices, friction devices and elasto-plastic hysteretic devices which have limitations related to durability, maintenance, ageing, need for replacement, installation complexity and change to structural geometry after severe earthquake. All the above mentioned limitations can be remedied by using SMA devices. SMAs are able to undergo huge recoverable strains of $10 \%$ with displaying no plasticity. A reorientation procedure called detwinning and twinning can take place among martensite variants at low temperatures. Many other phenomenon like shape memory effect, superelasticity also effect SMA behaviours as actuator ${ }^{1}$.

The aim of this paper is to discuss about SMAs and its application in civil engineering structures like cable stayed bridges, elevated highway bridges, simply supported bridges and buildings as seismic control device.

\section{SHAPE MEMORY ALLOY}

Shape memory alloys (SMA) are the alloys which has capability of regaining its shape by increasing the temperature. The temperature increase results in shape revival even under severe load applied which can result in high actuation energy density ${ }^{2}$. 


\subsection{SMA behaviours}

SMA has two crystalline structures or phases i.e. martensite and austenite. In martensite phase (i.e. stable at lower temperatures and higher stresses), SMA can be deformed into any shape. SMA undergoes transformation from martensite to austenite when heated. In austenite phase (i.e. constant at higher temperatures and lower stresses), SMA can "remember" shape it had before it was deformed ${ }^{1}$. However, martensite becomes stable at critical stress level which causes stress plateau and yielding demonstrated in Fig.1. Martensite can be constant due to stress applied but original undeformed shape can be regained by making austenite structure stable upon unloading ${ }^{3}$.

\subsection{Shape memory effect (SME)}

The SME is described as the process by which SMA can revert to their predetermined shapes upon heating ${ }^{5}$. The shape changes with temperature variation are mainly attributed to martensite phase transformation ${ }^{6}$.

\subsubsection{One way shape memory effect (OWSME)}

The material can be deformed when SMA is in its cold state (below $\mathrm{A}_{\mathrm{s}}$ ) till heated beyond transition temperature. The shape can change back to its undeformed state upon heating. There is no macroscopic shape change when cooled from high temperature with one way effect. A deformation is essential in creating low-temperature shape. Upon heating, conversion will initiate at $\mathrm{A}_{\mathrm{s}}$ and will get finished at $\mathrm{A}_{\mathrm{f}}$ (usually $2-20^{\circ} \mathrm{C}$, which depends on the loading conditions or the alloy). $\mathrm{A}_{\mathrm{s}}$ depends on alloy's type and will range from $-150{ }^{\circ} \mathrm{C}$ to $200{ }^{\circ} \mathrm{C}$.

\subsubsection{Two way shape memory effect (TWSME)}

Two way shape memory effect can be described as phenomenon by which materials can remember both shapes(i.e. both low temperature and high temperature state). The materials showing shape memory effect both during cooling and heating are pronounced having two way shape memory effect. It is seen even if external force is not applied. The reason for different material behaviour lies in training. Training means shape memory alloy will "remember" its low temperature shape at the time of heating by forgetting low temperature state. But it must be "trained" to "remember" for leaving some fragment of deformed low temperature state in high temperature state. A shaped, trained object will lose the two-way memory effect when heated above certain point. One way and Two way shape memory effect are demonstrated in Fig.2.

\subsection{Superelasticity}

Superelasticity is the phenomenon by which SMAs can recover their shape after unloading even it undergo large inelastic deformation ${ }^{7}$.

\section{Ni-Ti BASED SMA}

Among many alloy families based upon nickel- titanium composition, Nitinol, is mostly used for actuating and sensing devices in structural control systems. Titaniumnickel, can undergo strains upto $8 \%$, and will be strained upto $6 \%$ by regaining completely the undeformed shape when heated beyond activation temperature. It regains 80 $90 \%$ of stress applied at the beginning. It's density varies between $6.45 \mathrm{~g} / \mathrm{cm}^{3}$ to $6.5 \mathrm{~g} / \mathrm{cm}^{3}$. Ti-Ni alloys behaviour changes deeply with temperature, at ambient temperature the microstructure is fully martensitic, stress-strain behaviour displays large hysteresis loop identical to that of traditional steels and donot shows any recovery. Superelastic effect appears when materials are fully austenite at higher temperature. Nickel-titanium alloys are generally utilized in cold drawn wire or as bar stock ${ }^{8}$.

The SME can be "programmed" into SMA alloys with suitable thermal process. The process is straightforward and alloy formed is in austenite state and being heated to a particular temperature. Temperature and heating period depend upon alloy and the required characteristics. For Ni$\mathrm{Ti}$ alloy, $400^{\circ} \mathrm{C}$ temperature and $1-2$ minutes heating period is enough but normally $500{ }^{\circ} \mathrm{C}$ and over 5 minutes are utilized. Higher heat treatment periods and temperatures can increase element's actuation temperature and deliver a sharper thermal response but can reduce maximum output force.

Even though the process is straightforward, the heat treatment specification can be critical and usually requires experimental determination before the requirement are met ${ }^{2}$

\section{APPLICATION OF SMA AS SEISMIC CONTROL DEVICES}

\subsection{Bridges}

\subsubsection{SMA damping devices in vibration control of cable stayed bridges}

Sharabash and Andrawes ${ }^{1}$ applied SMA for seismic control of cable stayed bridge modelled by Nazmy and AbdelGhaffar $^{9}$ as shown in Fig.3.The SMA damping device used are in cable forms comprising of bundled or twisted SMA wires. These cables connect deck with the piers and towers. The seismic behaviour of SMA controlled bridge was compared with that of an identical bridge using shock transmission devices at deck-tower connection without SMA dampers. The results shows that SMA dampers were capable of lowering tower base shear, the maximum bridge displacement and tower base moments upto $65 \%, 65 \%$ and $69 \%$ respectively as compared to that with shock transmission devices.

The suggested SMA dampers setup for tower and pier connection is shown in Fig.4. It was found that there is improvement in overall bridge performance by increasing the number of SMA dampers which depends on the distribution of the dampers among pier and tower connection. Optimum allocation for the damping devices between the tower and pier connections was observed when $50 \%-75 \%$ of the dampers were allocated at the pier connections ${ }^{10}$. 


\subsubsection{Elevated Highway Bridge with SMA base}

\section{isolation system}

Wilde et al. ${ }^{11}$ studied elevated highway bridge (bridge model demonstrated in Fig.5.) fitted with superelastic SMA base isolation system in which comparative simulation of SMA isolation system and traditional isolation system accompanying three excitation levels are conducted. It is seen that SMA isolation system provide different response to excitation alongwith noticeable damping. SMA isolation system links deck and pier but relative motion occurs in traditional system. SMA goes through stress induced martensitic transformation for medium excitation level by allowing relative displacement compared to that of traditional isolation system. SMA bar goes into martensitic elastic range and maximum displacement is one fifth of traditional isolation system at severe loading. It is also seen that SMA isolation system shows damage energy less as compared to that of traditional system ${ }^{7,11}$.

\subsubsection{Bridges with SMA damper system}

Both martensite and superelastic SMAs are utilised as a damping element for bridge. A hypothetical analysis of vibration alleviation of combined cable-SMA damping system utilised in stay-cable bridge was conducted by Li et al. ${ }^{12}$ as shown in Fig.6. SMA damped cable's dynamic responses are simulated when it vibrates at first mode either at first few modes. It is seen that suggested superelastic SMA damping device was able to restrain vibration of cable in both the cases ${ }^{7,12}$.

\subsubsection{Seismic retrofit of simply supported bridge utilising SMA}

The three spans bridge supported by multicolumn bents with the SMA restrainer used. SMA restrainers are connected from pier cap upto beam's bottom flange.

It is seen that hinge displacement at abutment get reduced as compared to that with traditional steel restrainer. Large elastic strain range allows SMA restrainer for withstanding big deformation although remaining elastic. It is seen that SMA restrainers were effective in restricting bridge deck's response after calculation of simply supported bridge with multi span subjected to near field earthquake. The SMA restrainer's increased stiffness at large strains limits relative bridge openings ${ }^{3}$.

\subsection{Buildings}

\subsubsection{Buildings with SMA isolation system}

The Nitinol isolation system was developed and tested by Dolce et al. ${ }^{13}$ to analyze feasibility of Nitinol isolation system ${ }^{7}$.

The diagram of building's SMA isolation system is shown in Fig.7.Three stubs wired with superelastic SMA are linked to tubes. If there will be reciprocal movement among superstructure and foundation, SMA wire elongates and the wire was able to damp the vibration magnitude. Cyclic loading examinations found that isolation system have different stiffness alongwith loading intensity and higher capability for energy transmission filtration ${ }^{7}$.

\subsubsection{Frame structures with SMA braces}

The SMA braces were equipped in frame structure diagonally which is shown in Fig.8. A study was conducted for six story two bay by two bay steel frame equipped by Nitinol energy dissipation devices by Clark et al. ${ }^{14}$. Two cylindrical support post were wrapped around by 210 loops of Nitinol wire to assemble the braces. The result concluded that the suggested device had many properties like great adaptability, self-centering capability, simplicity in functioning techniques and higher stiffness for small displacements ${ }^{7,14}$.

\subsubsection{SMA connectors}

An exposed type column base alongwith SMA anchorage made of Nitinol SMA rods $(20-30 \mathrm{~mm})$ and steel bars demonstrated in Fig.9 was proposed by Tamai and Kitagawa ${ }^{15}$.It has been seen that SMA wires are efficient in lowering building's vibration anddistributing energy undergoing serious earthquake.

Martensite SMA tendons were used for primary load transfer component in steel beam-column connections by Leon et al. ${ }^{16}$ and connection is shown in Fig.10.The result shows that the connections display constant and repeating hysteresis of rotations upto $4 \%$ and SMA tendons were capable of maintaining upto $5 \%$ strain without undergoing permanent damage ${ }^{7,15}$.

\subsubsection{Structural reinforcement for earthquake retrofit}

Indirli et al. ${ }^{17}$ used superelastic SMA tie bars to restore the S. Giorgio Church Bell-Tower, which was severely affected during Oct. 15th 1996 earthquake as shown in Fig.11. The SMA tie bars, that runs throughout the tower's height and fixed to its foundation helps in strengthening structure and also increases the modal frequencies. The tower remained undamaged even after 2000 earthquake ${ }^{7,17}$.

\subsubsection{Shape restoration using superelastic SMAs}

Concrete beam's self-restoration using superelastic SMA wires was studied by Sakai et al. ${ }^{18}$. The results showed that mortar beam alongwith SMA regains fully even after undergoing serious crack. Effective technique of using superelastic SMA at University of Houston, for achieving large restoration force in stranded cable form was developed. Concrete beam ( 24 inch $\times 4$ inch $\times 6$ inch) strengthened by fourteen one by eight inch. diametersuperelastic stranded cables for achieving $2 \%$ prestrain by post-tensioning method.

Each cable consist of seven strands and every strand consist of seven SMA wires. Distinctive clamps are utilized for holding SMA strands/cables. Under elastic restoration force 
of SMA cables the crack was closed(Fig.13) upon load removal even after development of large crack (Fig.12) ${ }^{7,18}$.

\subsubsection{Structural vibration control with recentering} variable friction device undergoing near field earthquake

Two different RVFD configuration are proposed and both consist of a piezoelectric actuator, a friction generation unit and shape memory alloy wires. Both the configurations are shown in Fig. 14 and Fig. 15 respectively.

Three storied building equipped by RVFD among ground and first floor was subjected to different near field earthquake is considered and nonlinear time history analysis is conducted. The results show that RVFD is able to mitigate structure's peak displacement response alongwith sufficient improvement in acceleration response and is able to reduce significantly the structural residual deformations ${ }^{19}$.

\section{CONCLUSION}

This paper discusses basic shape memory alloy properties and its application in seismic control of structures like cable stayed bridges, simply supported bridges, elevated highway bridge, buildings etc. SMA have properties like superelasticity and shape memory effect that other alloys and metals do not have.Shape memory effect can be of one way shape memory effect and two way shape memory effect. The following conclusions are drawn after the study:i) SMA have the ability to recover their shape when temperature is increased.

ii) SMA when used as passive control device can overcome many limitations related to durability, ageing, installation complexity, maintenance, need for replacement and change to structural geometry after strong earthquake which are seen in normal passive control system.

iii) SMA are able to improve overall seismic performance and also have great adaptability, self centering capabilities.

iv) Superelastic SMA can be used for shape restoration purposes i.e. if there is formation of cracks in the concrete beam with SMA wires due to load application then the cracks can be closed by electrically heating SMA wires.

\section{REFERENCES}

[1] Motahari S.A., Ghassemieh M. and Abolmaali S.A., "Implementation of shape memory alloy dampers for passive control of structures subjected to seismic excitations", Journal of Constructional Steel Research 63 (2007), pp: 1570-1579.

[2] Kumar P.K. and Lagoudas D.C., "Introduction to Shape Memory Alloys", Springer Science+Business Media, LLC 2008.

[3] DesRoches R. and Delemont M., "Seismic retrofit of simply supported bridges using shape memory alloys", Engineering Structures 24 (2002), pp: 325-332.

[4] Wilde K., Gardoni P. and Fujino Y., "Base isolation system with shape memory alloy device for elevated highway bridges", Engineering Structures 22 (2000), pp: 222-229.

[5] Ozbulut O. E. and Hurlebaus S., "Evaluation of the performance of a sliding-type base isolation system with a NiTi shape memory alloy device considering temperature effects", Engineering Structures 32 (2010), pp: 238-249.

[6] Auricchio F. and Massarotti V., "One Way and Two Way-Shape Memory Effect: Thermo-Mechanical Characterization of $\mathrm{Ni}-\mathrm{Ti}$ wires",Universit adegliStudi di Pavia,AnnoAccademico 2007/2008.

[7] Song G., Ma N. and Li H.-N., "Applications of shape memory alloys in civil structures", Engineering Structures 28 (2006), pp: 1266-1274.

[8] Corbi O., "Shape memory alloys and their application in structural oscillations attenuation", Simulation Modelling Practice and Theory 11 (2003),pp: 387-402.

[9] Abdel-Ghaffar A.M. andNazmy A.M.,"3-D nonlinear seismic behaviour of cable-stayed bridges", Journal of Structural Engineering (ASCE) 117(11) (1991), pp: 345676.

[10] Sharabash A. M. and Andrawes B.O., "Application of shape memory alloy dampers in the seismic control of cable-stayed bridges", Engineering Structures 31 (2009), pp: 607-616.

[11] Wilde K, Gardoni P. and Fujino Y. "Base isolation system with shape memory alloy device for elevated highway bridges" Engineering Structures 22 (2000), pp:222-9.

[12] Li H., Liu M. and Ou J.P. "Vibration mitigation of a stay cable with one shape memory alloy damper", Structural Control and Health Monitoring 11(2004), pp:136.

[13] Dolce M., Cardone D. and Marnetto R., "SMA recentering devices for seismic isolation of civil structures", Proceedings of SPIE 4330(2001), pp: 238-49.

[14] Clark P., Aiken I., Kelly J., Higashino M. and Krumme R., "Experimental and analytical studies of shape memory alloy dampers for structural control", The international society for optical engineering 2445(1995).

[15] Tamai H. and Kitagawa Y., "Pseudoelasticbehavior of shape memory alloy wires and its application to seismic resistance member for building", Computational Materials Science 25(2002),pp:218-27.

[16] Leon R.T., DesRoches R., Ocel J. and Hess G,."Innovative beam column using shape memory alloys", Proceedings of SPIE 4330(2001), pp:227-37.

[17] Indirli $\mathrm{M}$ et al., "Demo application of shape memory alloy devices: the rehabilitation of S. Georgio Church Bell Tower", Proceedings of SPIE 4330(2001), pp:262-72.

[18] Sakai Y., Kitagawa Y., Fukuta T. and Iiba M., "Experimental study on enhancement of self-restoration of concrete beams using SMA wire"SPIE Smart Systems for Bridges, Structures, and Highways, At Newport Beach, California, USA(2003), pp:178-86.

[19] Ozbulut O. E. and Hurlebaus S., "Re-centering variable friction device for vibration control of structures subjected to near-field earthquakes", Mechanical Systems and Signal Processing 25 (2011), pp: 2849-2862. 


\section{FIGURES}

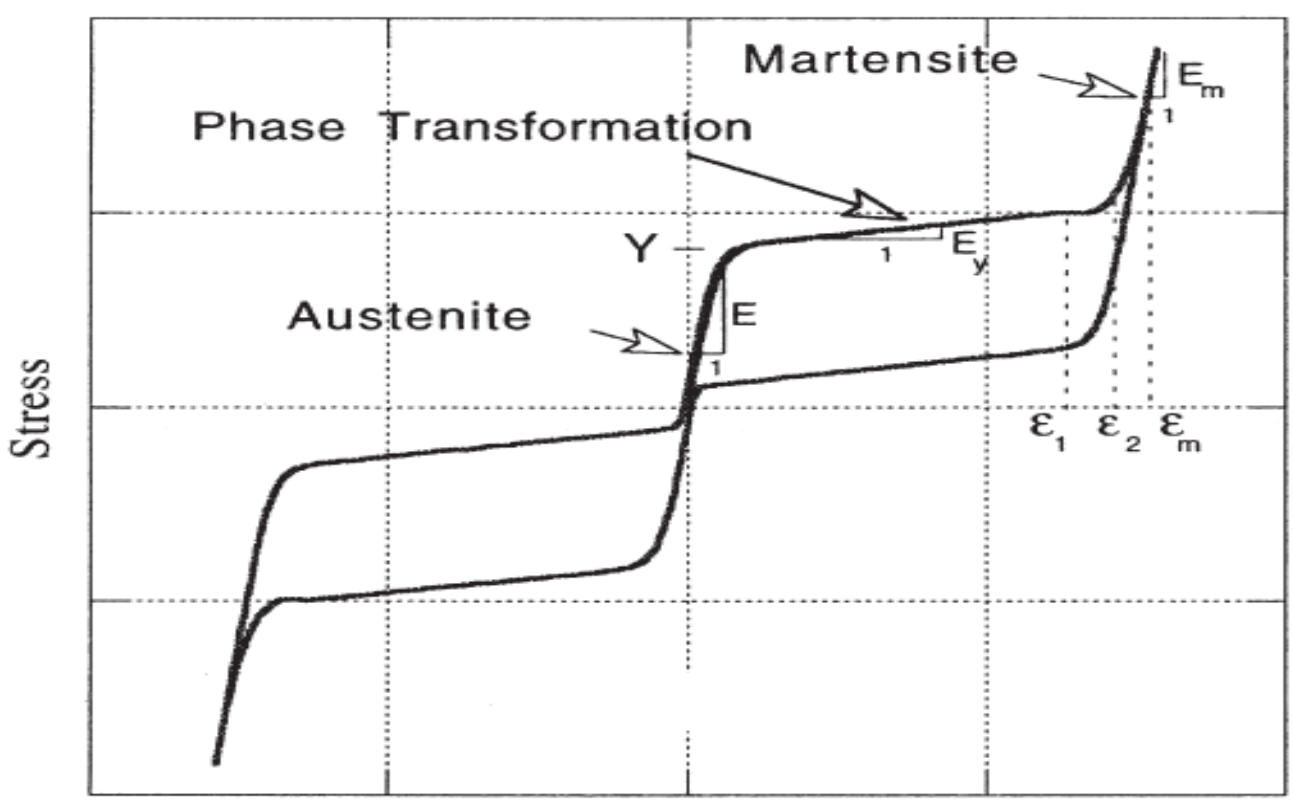

Fig.1. Stress-strain relations of shape memory alloy's extended hysteretic model ${ }^{4}$

a

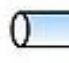

a

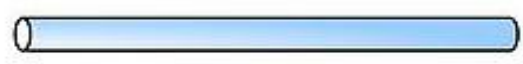

b

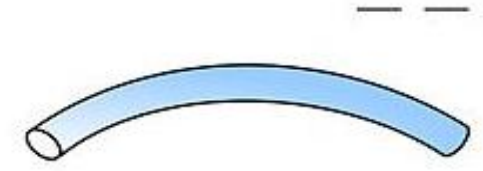

\section{(1)}

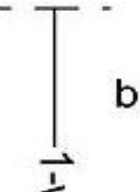

b

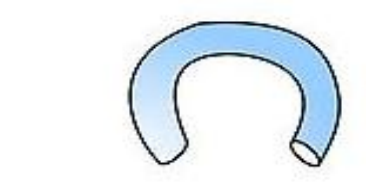

C

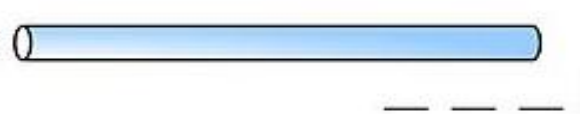

d
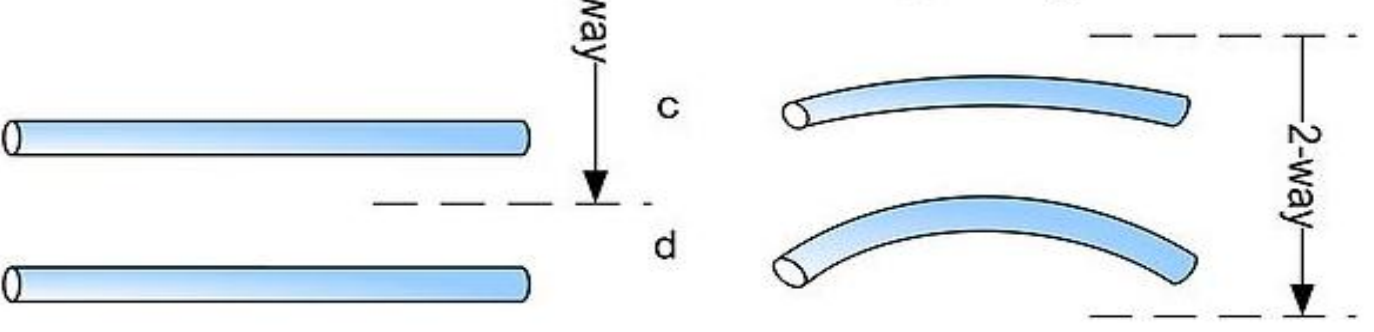

Fig.2. The process are very much likely: starts from martensite (a), adding changeable deformation for one-way effect or extreme deformation by irrevocable quantity for two way (b), heating specimen (c) again cooling it (d).

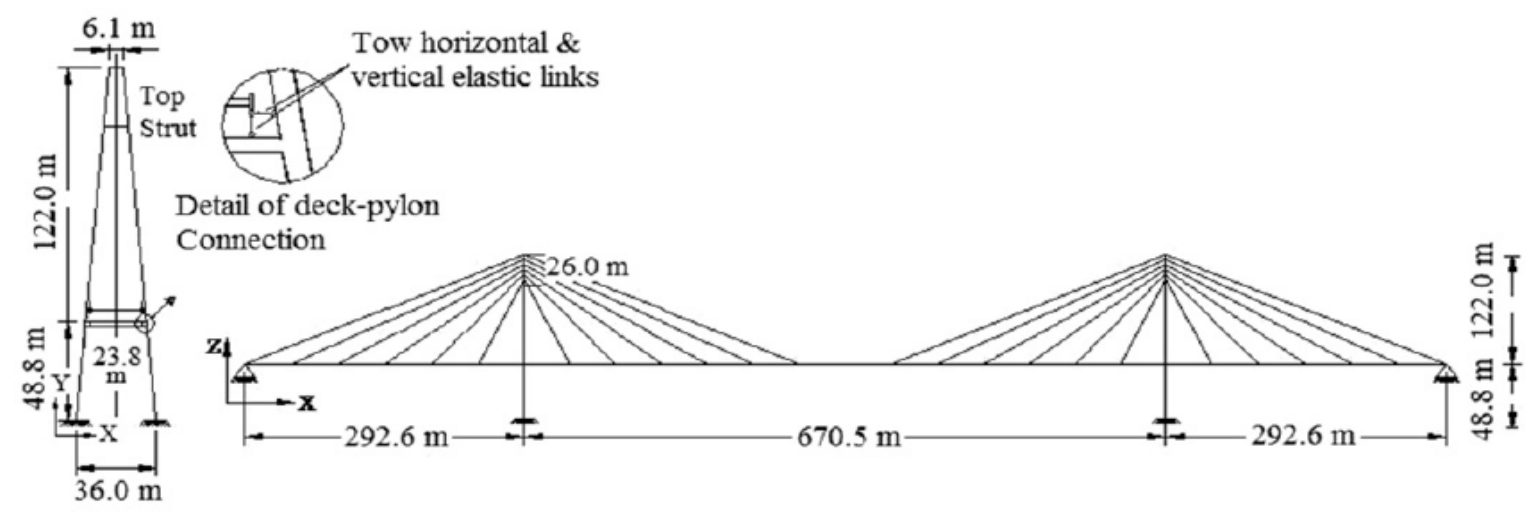

Fig.3. Adopted cable-stayed bridge ${ }^{10}$ 


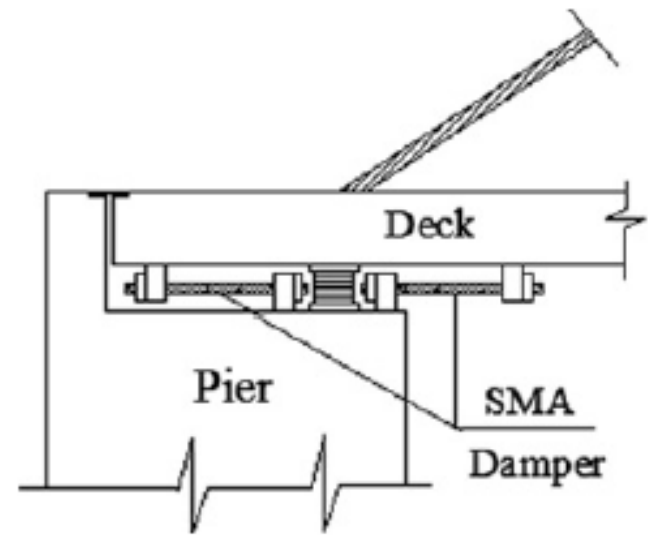

(a) Pier-Deck connection.

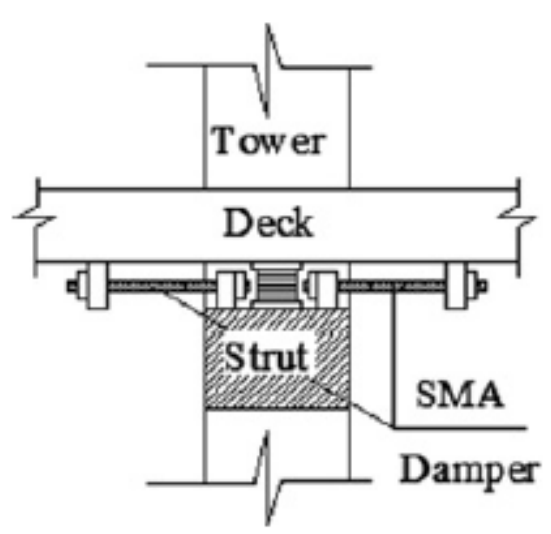

(b) Tower-Deck connection.

Fig.4. Suggested SMA damper setup for tower and pier connections ${ }^{10}$
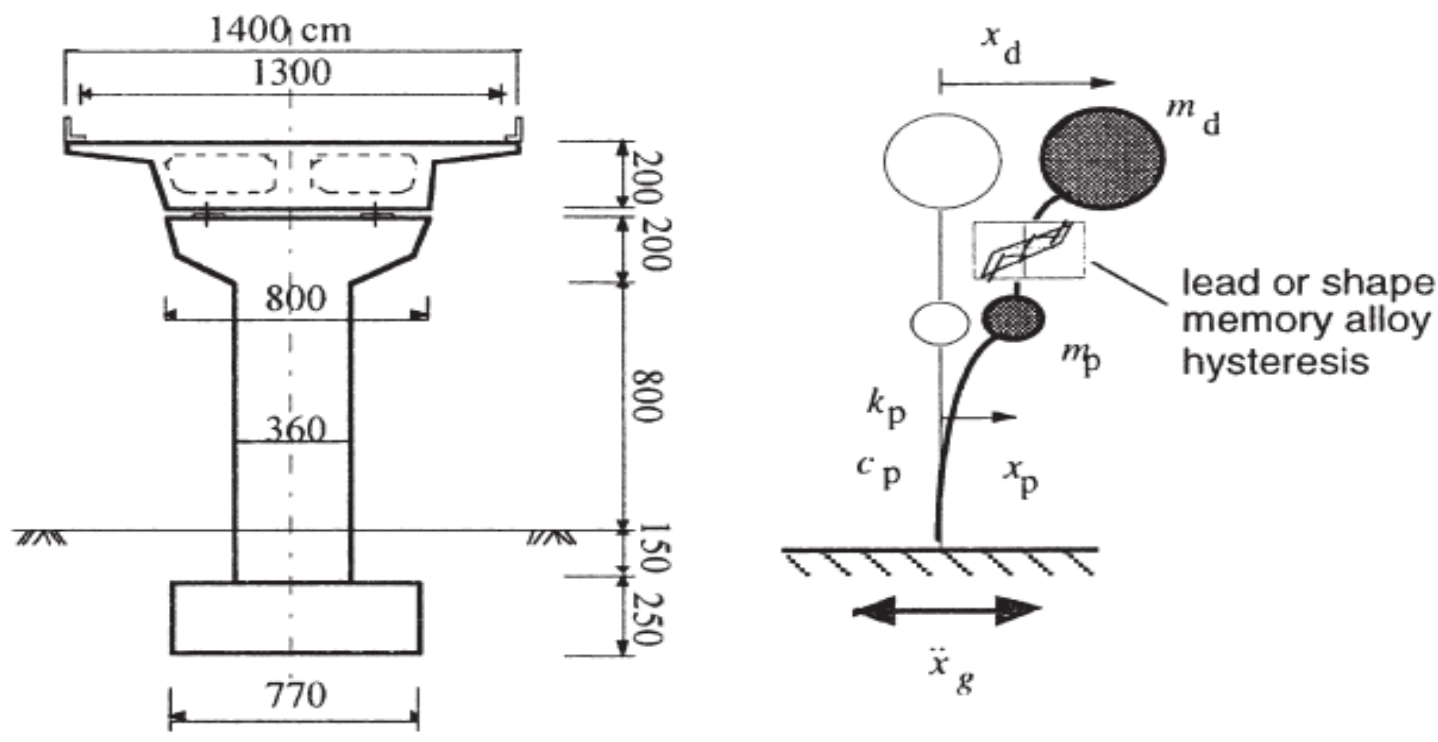

Fig.5. Model of the elevated highway bridge ${ }^{11}$

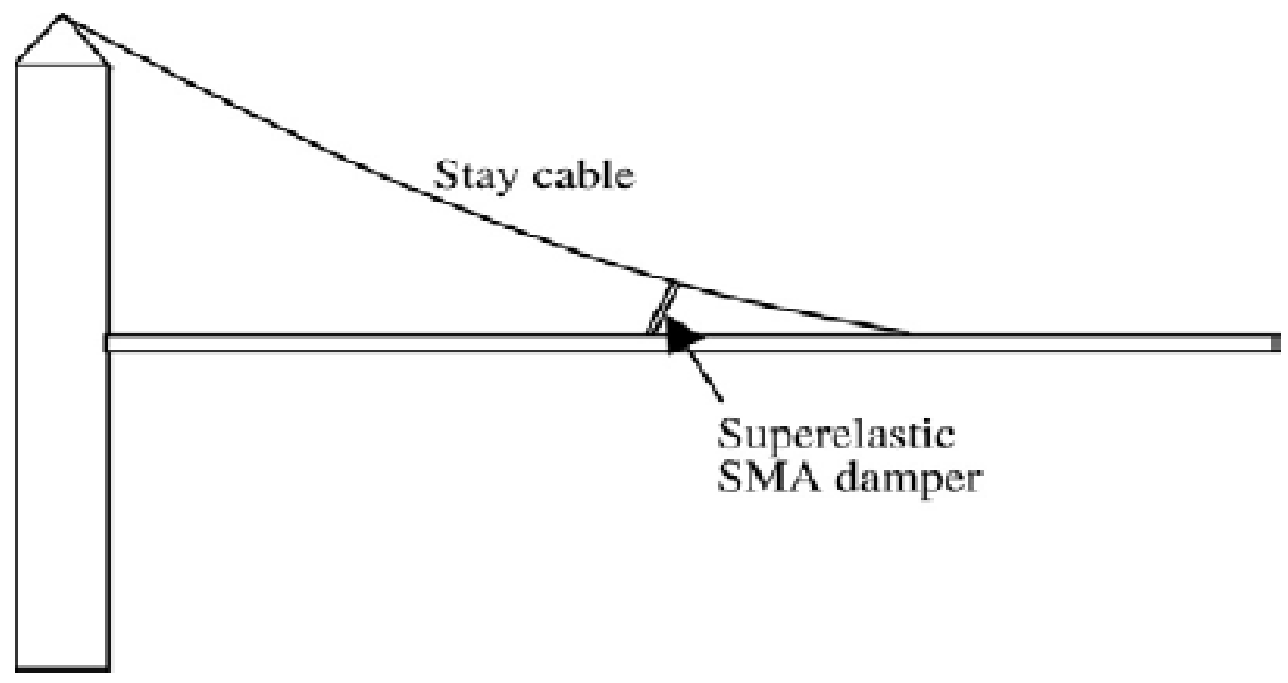

Fig.6. Stay-cable bridge with SMA damper ${ }^{7}$ 


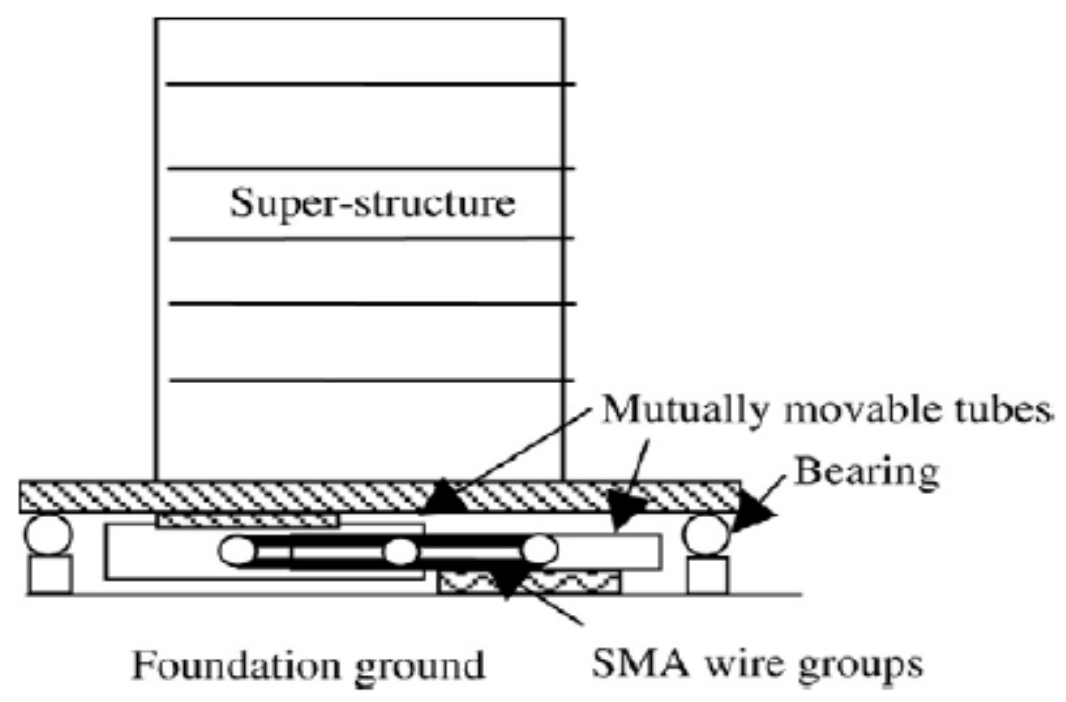

Fig.7. Buildings with SMA isolation system ${ }^{7}$

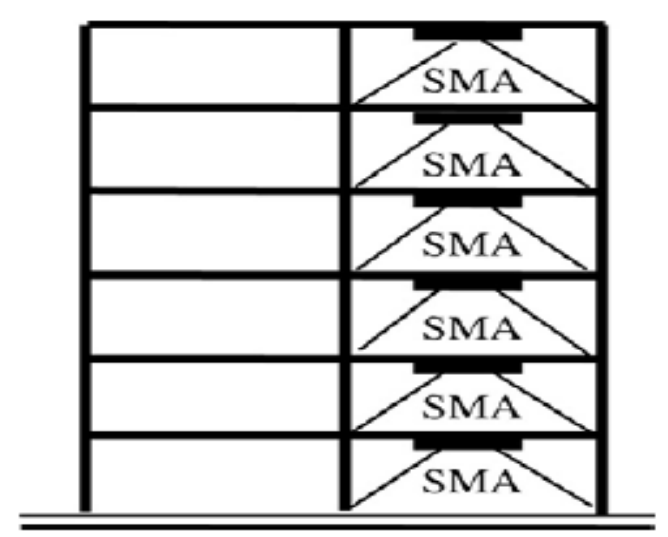

Fig.8. Reinforced frame structure support with $\mathrm{SMA}^{7}$

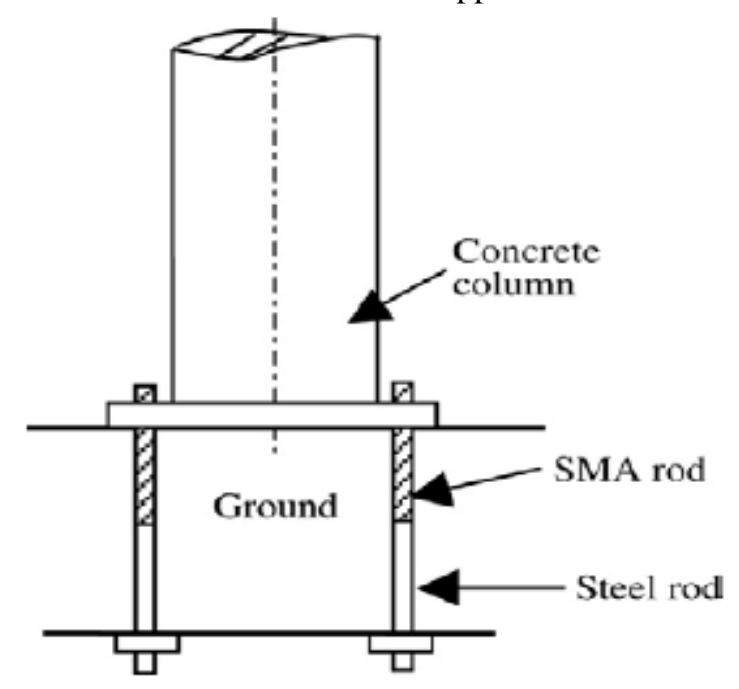

Fig.9. Column with SMA bar anchorage ${ }^{7}$ 


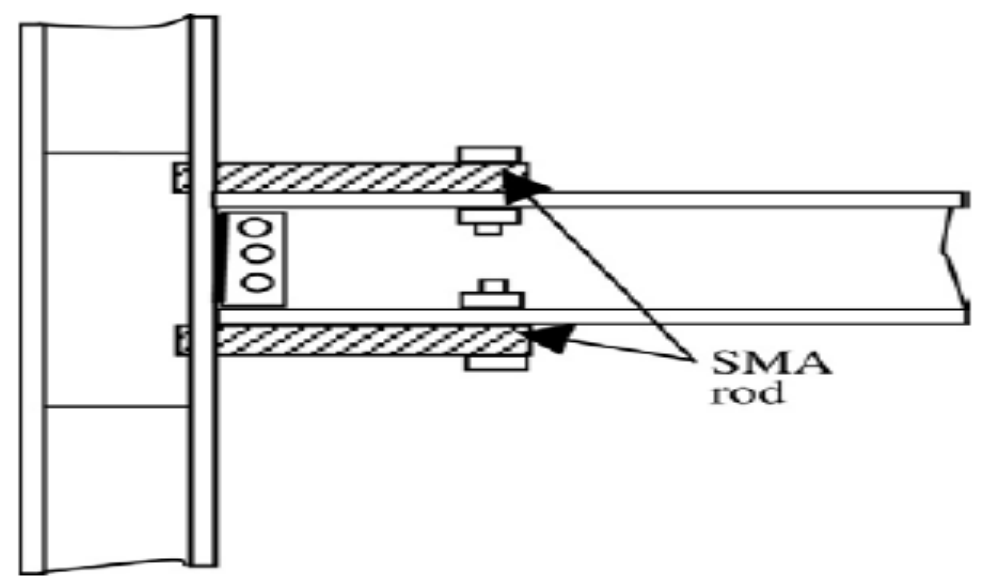

Fig.10. Steel structures with SMA connector ${ }^{7}$

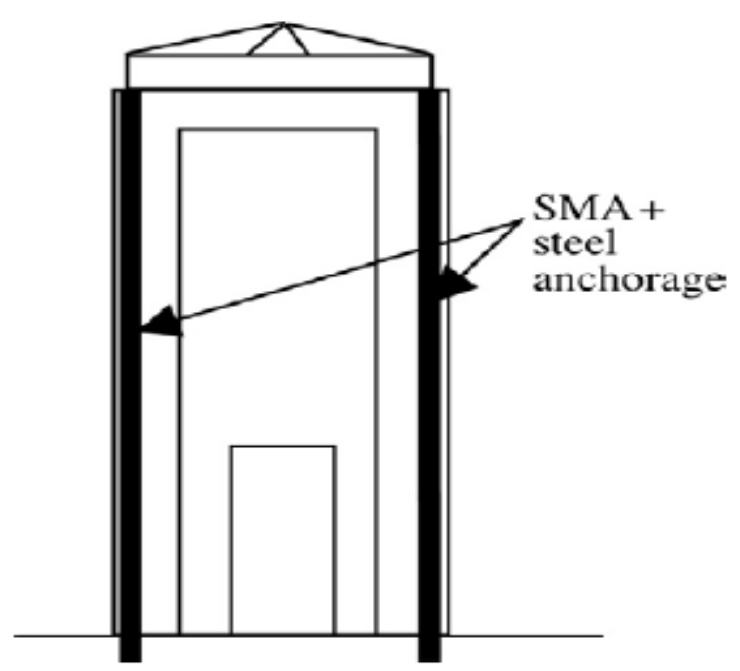

Fig.11. Bell tower retrofit utilising SMA anchorage ${ }^{7}$

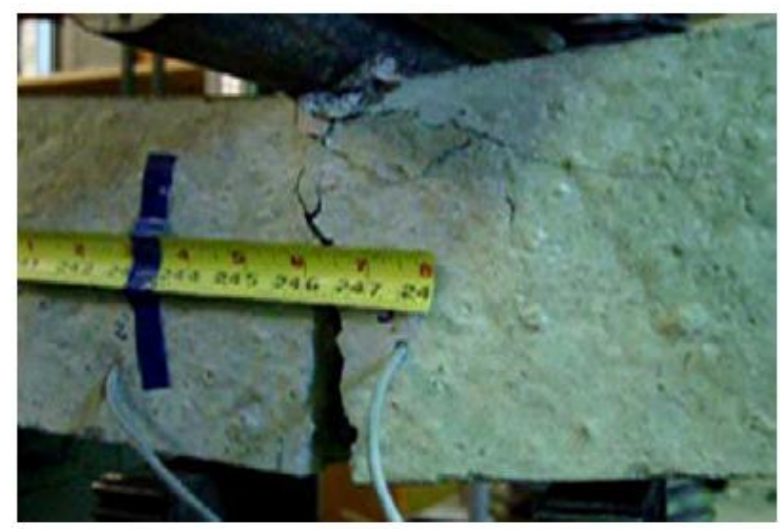

Fig.12. Occurance of large crack in loading test ${ }^{7}$ 


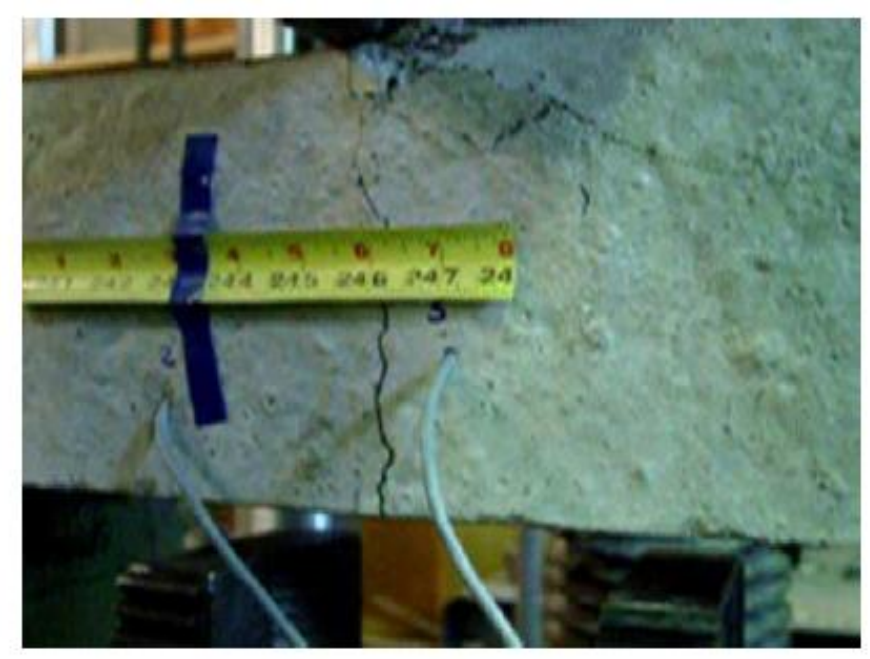

Fig.13. Closing of crack after loading test ${ }^{7}$
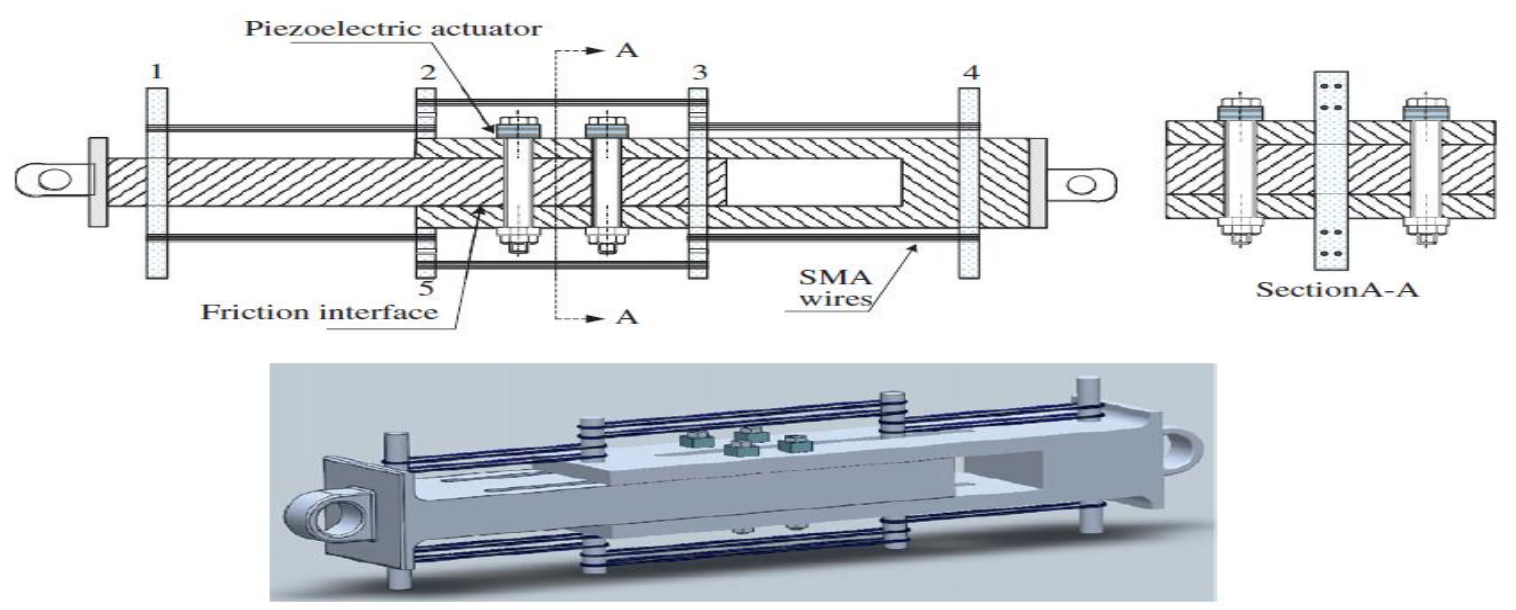

Fig.14. Diagrammatic demonstration with3D rendering of Configuration I RVFD are shown ${ }^{19}$
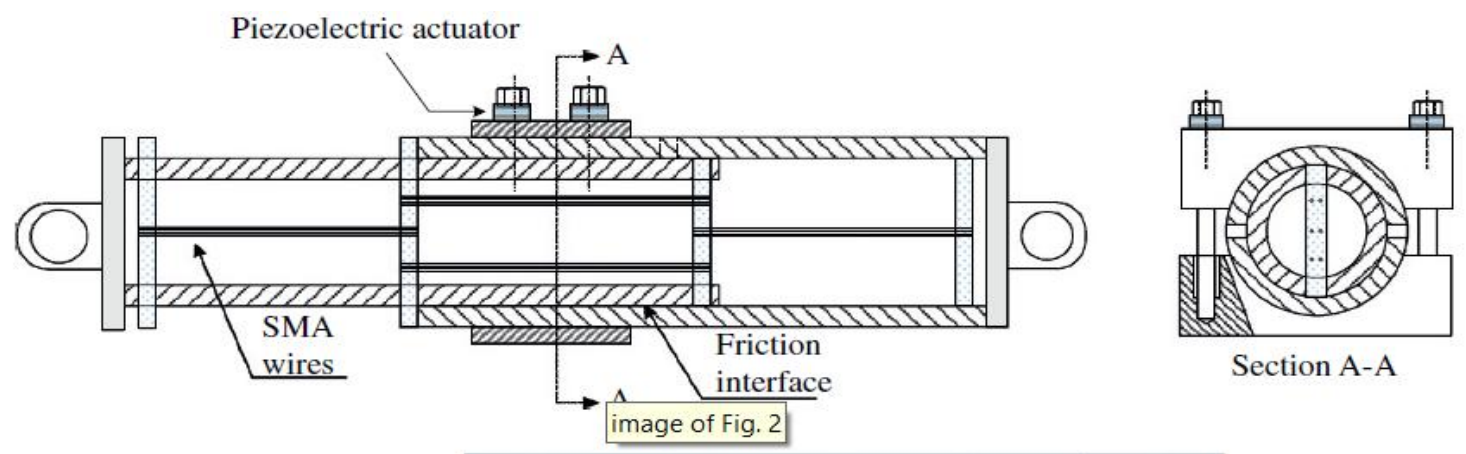

Section A-A

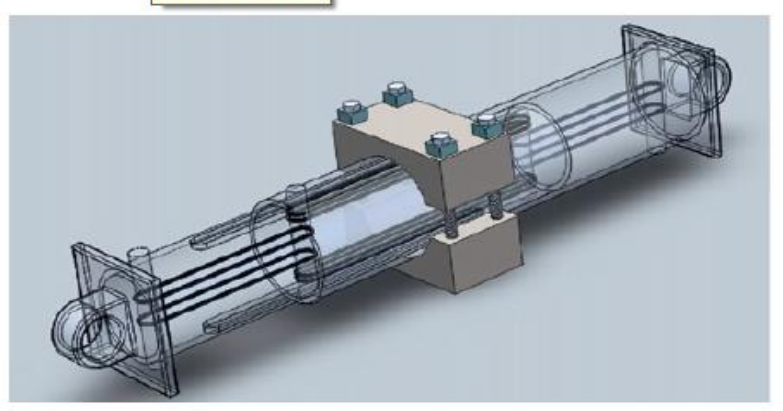

Fig.15. Diagrammatic demonstration and 3D rendering of Configuration II RVFD are shown ${ }^{19}$ 